\title{
An evaluation of knowledge, attitude and practices about prescribing fixed dose combinations among postgraduates of a rural tertiary health care teaching hospital
}

\author{
Manu Gangadhar*, Narasimhamurthy Kalenahally Muthahanumaiah, Padmanabha \\ Thiruganahalli Shivaraju
}

Department of Pharmacology, Adichunchanagiri Institute of Medical Sciences, B G Nagar, Nagamangala, Mandya 571448, Karnataka, India

Received: 23 September 2016

Revised: 27 October 2016

Accepted: 28 October 2016

*Correspondence to:

Dr. Manu Gangadhar,

Email: drmanugigu@gmail.com

Copyright: () the author(s), publisher and licensee Medip Academy. This is an openaccess article distributed under the terms of the Creative Commons Attribution NonCommercial License, which permits unrestricted noncommercial use, distribution, and reproduction in any medium, provided the original work is properly cited.

\begin{abstract}
Background: Fixed dose combinations (FDCs) is a combination product of two or more active pharmacological ingredients (APIs) in a single dosage form. There is lot of debate over rationality and irrationality of FDCs presently. This study was focused on medical postgraduates to evaluate their knowledge, attitude and practices about prescribing fixed dose combinations as they are the physicians who are future practitioners and it is up to them to misuse it or use it judiciously by prescribing rationally. The objective of the study was to evaluate knowledge, attitude and practices about prescribing fixed dose combinations among postgraduate medical students.
\end{abstract}

Methods: A cross-sectional questionnaire based study was conducted among postgraduate medical students of AIMS, B G Nagar, Nagamangala, Mandya, Karnataka, India.

Results: Total respondents were 124.81 participants $(65.32 \%)$ were males and 43 participants $(34.67 \%)$ were females. $73.38 \%$ of participants were aware of the term FDCs. Improvement in patient's compliance $(68.54 \%)$ and improved efficacy of individual drugs $(62.09 \%)$ were the advantages of using FDCs and irrational prescription of FDCs leading to drug resistance $(70.96 \%)$ and difficulty in dose adjustments of individual drugs (54.83\%) were the disadvantages mentioned. Knowledge of banned FDCs was lacking. More than half $(58 \%)$ of them were not able to mention a single banned FDC in India. Medical representatives $(45.16 \%)$, Internet $(27.41 \%)$, textbooks $(15.32 \%)$ were the most common sources of information of FDCs. Amoxicillin with clavulanic acid was the most common prescribed FDC (60.2\%).

Conclusions: Majority of the postgraduates have the knowledge about general aspects of FDCs, their advantages and disadvantages. However, knowledge about rational or irrational drugs, banned FDCs and availability of essential list is lacking. It is required that the concepts of rational drug use should be implemented in undergraduate curriculum vigorously and to strengthen their knowledge and skills to prescribe rationally.

Keywords: Attitude, Fixed dose combinations, Knowledge, Postgraduates, Practice

\section{INTRODUCTION}

Fixed dose combinations (FDCs) is a combination product of two or more active pharmacological ingredients (APIs) in a single dosage form. FDCs enhance the efficacy of individual drugs, decrease the chance of drug resistance, improve patient compliance and also decrease the pill burden on the patients. ${ }^{1}$ However, there are some disadvantages associated with the use of FDCs like irrational prescription, unsafe and ineffective treatment, prolongation or exacerbation of illness and higher cost of treatment. ${ }^{2}$ It may be administered as single entity products given along with or as a finished pharmaceutical product. When the combination has a proven advantage over single compounds administered separately in therapeutic effect, safety or compliance then FDC products are accepted. ${ }^{3}$ 
In developing countries there is growing concern about the increasing number of irrational FDCs, imposing unnecessary financial burden, increasing the occurrence of Adverse drug reactions (ADRs) which includes allergy, hospitalisation and ultimately quality of life is reduced. ${ }^{4}$ Combining two or more drugs in a single formulation causes changes in its safety, efficacy and bioavailability profile hence, FDCs are treated as new drugs. 5

The $19^{\text {th }}$ WHO Model Essential Drug List (April 2015) contains only 27 approved FDCs, while in our country, irrational drug combinations are available very easily and many among them available as over the counter (OTC) drugs. 6

A large number of FDCs are manufactured every year and hence the knowledge about prescribing FDCs is becoming important for better health outcomes. A study of knowledge, attitude and practice is an important tool to assess the lacunae and benefits about a subject in the community, so that to improve the outcome effective steps can be taken in that direction. Tertiary care teaching hospitals play a dual role in terms of providing health care facilities to the patients and also educating medical students. Postgraduates are involved primarily in the management of patients at tertiary care teaching hospitals, so their awareness about prescribing medicines is of prime importance for treating patients.

Henceforth, the present study was conducted to evaluate knowledge, attitude and practices about prescribing FDCs among postgraduates at a tertiary teaching hospital.

\section{METHODS}

A cross-sectional questionnaire based study was conducted among postgraduate medical students of AIMS, BG Nagar, Nagamangala, Mandya, Karnataka, India. All postgraduates from first year to final year with sample size of 124 .

\section{Data collection procedures}

A cross-sectional questionnaire based study was conducted in AIMS, B G Nagar, with an aim to evaluate the knowledge, attitude and practice of prescribing fixed dose combinations (FDCs) among postgraduate medical students. The study was conducted after obtaining the permission from the Institutional Ethical Committee.

Objectives and procedure of the study was explained to the participants and those who were willing to fill the informed consent form were included in the study. A feedback questionnaire covering various aspects of FDCs was distributed among the participants. The information pertaining to FDCs, whether they prescribe them commonly, do they provide therapeutic benefits to patients, does it improve patient's compliance and efficacy of individual drugs, whether they reduce cumulative toxicity or increase the incidence of adverse drug reactions or increases the chance of drug resistance, any FDC drug which is banned in our country, what was the source of information regarding FDCs, any interventions can reduce the prescription of irrational FDCs, the most commonly prescribed FDCs by them and to which condition they commonly prescribe FDCs. The filled questionnaire feedbacks were retrieved from the participants.

Quality control was maintained as per the standard protocol.

\section{Statistical analysis}

The returned questionnaires were checked for completeness of the data and the descriptive data were expressed in percentages.

\section{RESULTS}

Total respondents were 124 . Among them 81 participants $(65.32 \%)$ were males and 43 participants $(34.67 \%)$ were females.

Table 1: Knowledge about fixed dose combinations.

\begin{tabular}{|llllll|}
\hline Q. & Questions & Yes & \multicolumn{3}{l|}{ No } \\
\hline 1 & No's & $\%$ & No's & $\%$ \\
\hline 2 & $\begin{array}{l}\text { FDC means fixed } \\
\text { drug combination }\end{array}$ & 33 & 26.61 & 91 & 73.38 \\
\hline 3 & $\begin{array}{l}\text { FDC means fixed } \\
\text { dose combination }\end{array}$ & 91 & 73.38 & 33 & 26.61 \\
\hline & $\begin{array}{l}\text { FDCs lead to } \\
\text { improvement in } \\
\text { patients } \\
\text { compliance }\end{array}$ & 85 & 68.54 & 39 & 31.45 \\
\hline 4 & $\begin{array}{l}\text { FDCs lead to } \\
\text { improved efficacy } \\
\text { of individual drugs }\end{array}$ & 77 & 62.09 & 47 & 37.90 \\
\hline 5 & $\begin{array}{l}\text { Irrational } \\
\text { prescription of } \\
\text { FDCs can lead to } \\
\text { drug resistance }\end{array}$ & 88 & 70.96 & 36 & 29.03 \\
\hline 6 & $\begin{array}{l}\text { Dosage alteration } \\
\text { of one drug is not } \\
\text { possible without } \\
\text { alteration of other } \\
\text { drug }\end{array}$ & 68 & 54.83 & 56 & 45.16 \\
\hline 7 & $\begin{array}{l}\text { FDCs may reduce } \\
\text { financial burden on } \\
\text { the patient }\end{array}$ & 54 & 43.54 & 70 & 56.45 \\
\hline 8 & $\begin{array}{l}\text { FDCs increases the } \\
\text { incidence of } \\
\text { adverse effects }\end{array}$ & 42 & 33.87 & 82 & 66.12 \\
\hline $\begin{array}{l}\text { Do you know the } \\
\text { availability of } \\
\text { WHO Essential } \\
\text { medicine list }\end{array}$ & 25 & 20.16 & 99 & 79.83 \\
\hline
\end{tabular}


Table 2: Knowledge about rationality of drugs.

\begin{tabular}{|llllll|}
\hline \multirow{2}{*}{ No. } & FDCs & \multicolumn{2}{c}{ Rational } & \multicolumn{2}{c|}{ Irrational } \\
\hline A & $\begin{array}{l}\text { Amoxicillin }+ \\
\text { clavulanic acid }\end{array}$ & 117 & 94.35 & 07 & 5.64 \\
\hline B & $\begin{array}{l}\text { Ampicillin }+ \\
\text { cloxacillin }\end{array}$ & 98 & 79.03 & 26 & 20.96 \\
\hline C & $\begin{array}{l}\text { Ofloxacin }+ \\
\text { ornidazole }\end{array}$ & 89 & 71.77 & 35 & 28.22 \\
\hline D & $\begin{array}{l}\text { Diclofenac }+ \\
\text { paracetamol + } \\
\text { serratiopeptidase }\end{array}$ & 114 & 91.93 & 10 & 8.06 \\
\hline E & $\begin{array}{l}\text { Nimesulide }+ \\
\text { paracetamol }\end{array}$ & 65 & 52.41 & 59 & 47.58 \\
\hline F & $\begin{array}{l}\text { Pantoprozole }+ \\
\text { domperidone }\end{array}$ & 73 & 58.87 & 51 & 41.12 \\
\hline
\end{tabular}

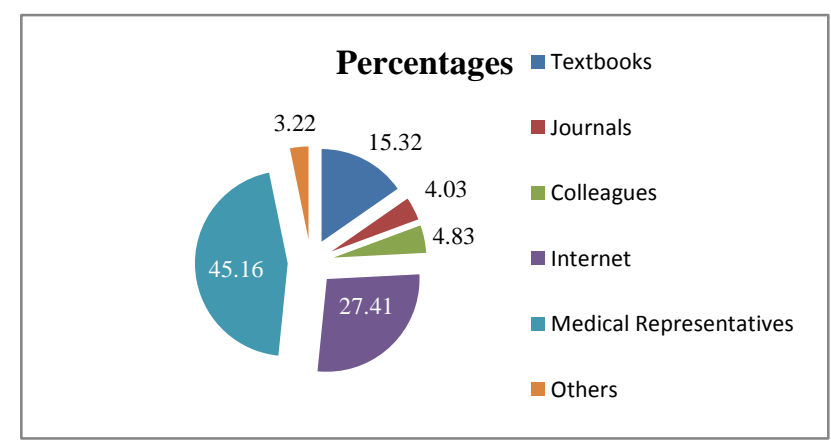

Figure 1: Sources of fixed dose combinations information.

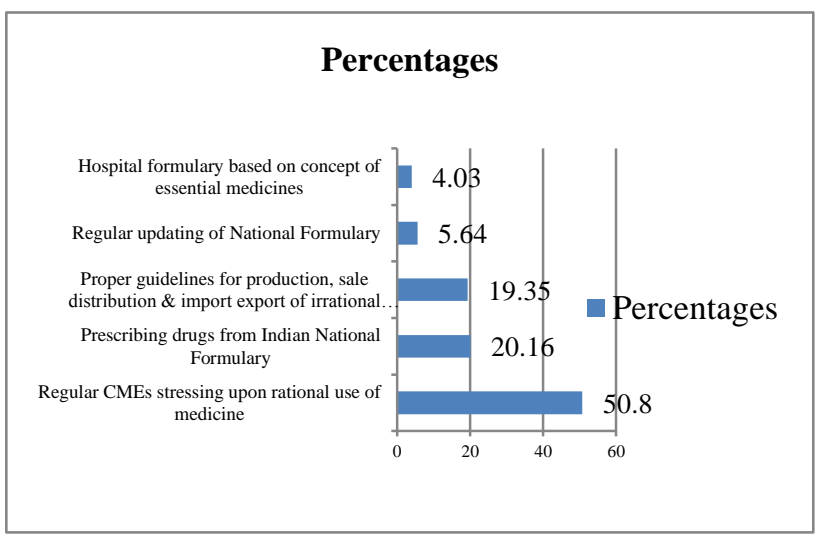

Figure 2: Analysis of the perception of various interventions to reduce irrational fixed dose combinations.

\section{DISCUSSION}

The present study evaluates the knowledge, attitude and practice about prescribing FDCs among postgraduate medical students in a rural tertiary care teaching hospital. This study would take into consideration about the existing knowledge and understanding of postgraduate medical students about various issues concerned with prescribing FDCs and to promote and improve the rational use of combination of drugs to improve health care services.

Table 3: Attitude and practice of fixed dose combinations.

\begin{tabular}{|c|c|c|c|c|c|}
\hline \multirow{2}{*}{$\begin{array}{l}\text { Q } \\
\text { No. }\end{array}$} & \multirow{2}{*}{$\begin{array}{l}\text { Attitude and } \\
\text { practice of } \\
\text { FDCs }\end{array}$} & \multicolumn{2}{|l|}{ Yes } & \multicolumn{2}{|l|}{ No } \\
\hline & & No's & $\%$ & No's & $\%$ \\
\hline 1 & $\begin{array}{l}\text { Do you think } \\
\text { FDCs should be } \\
\text { allowed to be } \\
\text { marketed }\end{array}$ & 118 & 95.16 & 06 & 4.83 \\
\hline 2 & $\begin{array}{l}\text { Do you } \\
\text { prescribe FDCs }\end{array}$ & 98 & 79.03 & 26 & 20.96 \\
\hline \multirow{3}{*}{3} & \multirow{3}{*}{$\begin{array}{l}\text { Most common } \\
\text { FDC prescribed }\end{array}$} & \multicolumn{2}{|c|}{$\begin{array}{l}\text { Amoxicillin + } \\
\text { clavulanic } \\
\text { acid }\end{array}$} & \multicolumn{2}{|c|}{$\begin{array}{l}59(60.2 \%) \\
n=98\end{array}$} \\
\hline & & \multicolumn{2}{|c|}{$\begin{array}{l}\text { Nimesulide + } \\
\text { Paracetamol }\end{array}$} & \multicolumn{2}{|c|}{$\begin{array}{l}21(21.42 \%) \\
\mathrm{n}=98\end{array}$} \\
\hline & & \multicolumn{2}{|c|}{$\begin{array}{l}\text { Pantoprozole } \\
+ \\
\text { domperidone }\end{array}$} & \multicolumn{2}{|c|}{$\begin{array}{l}18(18.36 \%) \\
n=98\end{array}$} \\
\hline \multirow{3}{*}{4} & \multirow{3}{*}{$\begin{array}{l}\text { Most common } \\
\text { condition for } \\
\text { which FDCs was } \\
\text { prescribed }\end{array}$} & \multicolumn{2}{|c|}{ Infections } & \multicolumn{2}{|c|}{$44(44.89 \%)$} \\
\hline & & \multicolumn{2}{|c|}{ Pain and fever } & \multicolumn{2}{|c|}{$30(30.61 \%)$} \\
\hline & & \multicolumn{2}{|c|}{ Acute gastritis } & \multicolumn{2}{|c|}{$24(24.48 \%)$} \\
\hline
\end{tabular}

In the present study $73.38 \%$ of participants were aware of the term FDCs. Improvement in patient's compliance $(68.54 \%)$ and improved efficacy of individual drugs $(62.09 \%)$ were mentioned as the advantages of using FDCs and the disadvantages is that irrational prescription of FDCs lead to drug resistance $(70.96 \%)$ and difficulty in dose adjustments of individual drugs $(54.83 \%$ ) (Table 1). Sharma $\mathrm{K}$ et al., study ${ }^{7}$ conducted among dental clinicians and residents had similar results regarding advantages and disadvantages of FDCs. FDCs are associated with many advantages like synergistic action and increased efficacy (e.g. antihypertensives, cotrimoxazole), reduced pill burden and cost of therapy (not always), reduced adverse effects (levodopa with carbidopa, thiazides with potassium sparing diuretics), convenience (anti-tubercular drug combinations) and better patent compliance. ${ }^{8}$ However, incompatible pharmacokinetics, increased toxicity and cost, use of sub therapeutic dose of individual drugs are some of the disadvantages of using FDCs.

Knowledge about the rationality of commonly prescribed FDCs was lacking as they considered many of the combinations mentioned were rational (Table 2). Only amoxicillin with clavulanic acid was the approved FDCs among the list mentioned in Table 2 according to WHO essential drug list. ${ }^{6}$ Comparative studies among patients, physicians and pharmacists, Patil PJ et al showed that there was contrast thinking on the rationality of FDCs. Pharmacists and physicians think all FDCs are rational but the patients think it is irrational. ${ }^{9}$ 
Knowledge of banned FDCs was lacking in these postgraduates. More than half $(58 \%)$ of them were not able to mention a single banned FDC in India. The government of India has banned a total of 336 drugs and their combinations with other drugs for manufacturing and marketing in India. ${ }^{10}$ Knowledge about the banned drugs/FDCs is very important as lack of this knowledge and prescribing of these agents may lead to serious, adverse drug reactions.

Medical representatives $(45.16 \%)$, internet $(27.41 \%)$, textbooks $(15.32 \%)$ were the most common sources of information of FDCs for the postgraduates (Figure 1). Alareefi MA et al, study mentions that physicians admitted that they were bound to prescribe certain medicine at the cost of getting some incentives in the form of free samples, gifts or various kinds of supports. ${ }^{11}$

Most of the postgraduates believed that regular continuous medical education (CMEs) stressing upon rational use of medicine could sensitize them to the rational FDCs (Figure 2). 95.16\% of participants opined that FDCs should be allowed to be marketed and $79.03 \%$ of them prescribe FDCs regularly. Amoxicillin with clavulanic acid was the most common prescribed FDCs $(60.2 \%)$ and infections was the most common condition $(44.89 \%)$ for which they prescribed FDCs. However, they lack in the knowledge towards prescribing FDCs rationally.

It is required that the concepts of rational drug use should be implemented among students in undergraduate curriculum vigorously and also it is required to strengthen the mechanism for continuing professional development of these prescribers to update their knowledge and skills to prescribe rationally. By giving educational intervention through conducting frequent continued medical education (CMEs), the knowledge of these postgraduate students can be increased substantially about all the aspects of FDCs so that they practice rational use of drugs.

\section{CONCLUSION}

Majority of the postgraduates have the knowledge about general aspects of FDCs, their advantages and disadvantages. However, knowledge about rational or irrational drugs, banned FDCs and availability of essential list is lacking. Lack of utilization of drug information and its authentic sources could be the most common cause of poor knowledge. Other factors which may be responsible for their lack in knowledge towards FDCs may be lack of sensitization during undergraduate training, lack of education sessions about FDCs. Moreover, dependence for medical information by the prescribers on medical representatives ultimately leads to irrational use of drugs. So it is required that the concepts of rational drug use should be implemented in undergraduate curriculum vigorously and to strengthen the mechanism for continuing professional development of these prescribers to update their knowledge and skills to prescribe rationally.

The limitation of our study was that the sample size was very small, representing a single private medical institute which can be biased. A multicentre study with higher sample size will be beneficial in assessing the awareness of FDCs among medical postgraduates.

\section{ACKNOWLEDGEMENT}

We would like to express our gratitude to all the medical postgraduates who participated in this study for spending their time to answer our questionnaire that helped us to complete our study successfully and we are also thankful to the Institutional ethical committee of AIMS, BG Nagar, Mandya, Karnataka India that permitted to conduct this study.

Funding: No funding sources

Conflict of interest: None declared

Ethical approval: The study was approved by the Institutional Ethics Committee

\section{REFERENCES}

1. WHO drug information volume 17, No. 3: World Health Organization (Geneva); 2003. 85p. Available from: http://apps.who.int/medicinedocs/en/d/Js4955e.

2. Kastury N, Singh S, Ansari KU. An audit of prescription for rational use of fixed dose drug combinations. Indian J Pharmacol. 1999;31:367-9.

3. Sreedhar D, Subramanian G, Udupa N. Combination drugs: are they rational? Curr Sci. 2006:91:406.

4. Baiardini I, Guerra L, Pasquali M, Bonadonna P, Passalaqua G, Canonica GW. Quality of life in patients with adverse reactions to drugs: preliminary results from a new questionnaire. J Allergy Clin Immunol. 2004;113(2):S70.

5. Deshmukh P, Purohit S. Rationality of fixed dose combinations: necessity to weed out the irrational combinations mushrooming in pharmaceutical industry. Pharm Rev. 2008; 6

6. World Health Organisation. Essential drugs: 19th updated WHO Model List 2015. Available from: http://www.who.int/medicines/publications/essential medicines/en/.

7. Sharma K, Sharma A, Singh V, Pilania D, Sharma YK. Irrational fixed dose combinations and need for intervention: understanding of Dental clinicians and residents. Journal of Clinical and Diagnostic Research. 2014;8(12):49-52.

8. Shrivastava SK. Chapter 90 Fixed Dose Combinations: General comments and complete textbook of medical pharmacology. Sirmour, India: Avichal Pub Company. 2012;2:1413-4.

9. Patil P J, Patil M J, Patil V R, Deshmukh T A, Band S S. A Survey on Awareness of Fixed Dose Combinations (FDCs) among Patients, Physicians 
and Pharmacists at Pune and Beed (India). Indian Journal of Pharmacy Practice. 2013;6(3):49-52.

10. The Ministry of Health and Family Welfare. List of fixed dose combinations (FDC) banned 10/3/2016. Available from: www.drrohanjshenoy.com/wp-
content/.../2016/.../FDCs-banned-on-10-March2016.p.

11. Al-areefi MA, Hassali MA, Izham M. Physician's perceptions of medical representative visits in Yemen: a qualitative study. BMC Health Serv Res. 2013; 13(1):1.

Cite this article as: Manu G, Narasimhamurthy KM, Padmanabha TS. An evaluation of knowledge, attitude and practices about prescribing fixed dose combinations among postgraduates of a rural tertiary health care teaching hospital. Int $\mathrm{J}$ Basic Clin Pharmacol 2016;5:2476-80. 